\title{
LA UNIÓN EUROPEA Y EL ESTADO SOCIAL
}

\author{
RAFAel Gómez-FerRer Morant \\ Catedrático de Derecho Administrativo \\ Universidad Complutense de Madrid
}

\begin{abstract}
RESUMEN
La Constitución incorpora el resultado de dos siglos de evolución, a partir de la Revolución francesa, que ha culminado con la configuración del Estado social y democrático de derecho. La incorporación de España a la Comunidad Económica Europea (Unión Europea) ha contribuido a la efectividad del Estado social a medida que el derecho de la Unión ha ido convergiendo con el derecho de los Estados que la componen. Esta convergencia ha potenciado la consecución de objetivos en materia social, de medio ambiente y de protección de los derechos de los consumidores, con especial trascendencia en relación con los créditos hipotecarios.
\end{abstract}

Palabras clave: Estado social y democrático de derecho; derecho de la Unión Europea; convergencia; consecución de objetivos.

\begin{abstract}
The Constitution incorporates the result of two centuries of evolution, from the French Revolution, which has culminated in the setting of the social and democratic State of Law. The incorporation of Spain to the European Economic Community (European Union) has contributed to the effectiveness of the social State as the Law of the Union has been converging with the Law of the States that compose it. This convergence has enhanced the achievement of objectives in social, and environmental matters, and in protection of consumer rights, with particular significance in relation to mortgage loans.
\end{abstract}

Key words: social and democratic State of Law; European Union Law; convergence; goals achievement. 


\section{SUMARIO}

I. El Estado social y DEMOcRÁtico DE DERECho Diseñado POR la CONSTituCión.

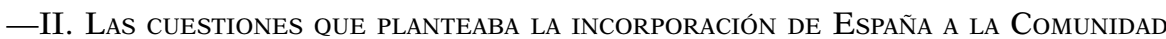
ECONÓMICA EUROPEA. LA CONVERGENCIA COMO VÍA DE SOLUCIÓN.-III. LA APORTACIÓN DE LA UNión EuRopea a La EFECTIVIDAd del Estado SOCIAL Y DEMOCRÁTICO DE DERECHO: 1. Introducción. 2. La lucha contra la corrupción. 3. La efectividad de los principios rectores de la política económica y social.-IV. CoNCLUSIón.

I. El Estado SOCIAL Y DEMOCRÁtico DE DERECHO DISEÑAdo POR LA CONSTITUCIÓN

La Constitución española incorpora el resultado de dos siglos de evolución, a partir de la Revolución francesa, que han permitido diseñar el Estado social y democrático de derecho que consagra su artículo $1^{\circ}$.

Se trata de un Estado producido por acumulación de conquistas en el terreno de los derechos de los ciudadanos: de cuño liberal, concebidos inicialmente como derechos de carácter negativo frente al Estado; de tipo democrático, conceptuados como libertades de carácter positivo concretadas en el sufragio universal, derecho a los cargos y funciones públicas, derecho de petición; y de carácter económico y social, que en cuanto son «derechos» de prestación frente al Estado requieren evaluar las posibilidades reales de satisfacerlos, por lo que se configuran como "principios rectores de la política social y económica», si bien con algunas excepciones, como sucede con el derecho a la tutela judicial efectiva y el derecho a la educación, que consagran, respectivamente, los artículos 24 y 27 de la Constitución.

Estos derechos son la concreción de unos valores como la libertad y la igualdad ya presentes en la Declaración de Derechos del Hombre y del Ciudadano, cuya formulación se ha ido completando en el tiempo con los de justicia y pluralismo político.

Estos valores y derechos se incluyen en la Constitución, cuyo artículo $1^{\circ}$ propugna como valores superiores del ordenamiento jurídico la libertad, la justicia, la igualdad y el pluralismo político y cuyo artículo 10, de capital importancia, establece que la dignidad de la persona humana, los derechos inviolables que le son inherentes, el respeto a la ley y a los derechos de los demás, son el fundamento del orden político y de la paz social ${ }^{1}$.

1 Sobre este télos ideológico véase R. Gómez Ferrer-Morant (1999), «Incidencia de la Constitución sobre el Derecho Administrativo», Revista de Administración Pública, 150, págs. 159 a 209 , esp. 160 y ss. 
En síntesis, el Estado social y democrático de derecho evidencia un compromiso entre la libertad y la igualdad. La libertad en el mundo económico conduce a la desigualdad y precisamente el compromiso entre esta libertad y la igualdad se instrumenta por medio de los derechos y de los principios rectores de la política social y económica, tal y como los reconoce o establece la Constitución ${ }^{2}$.

Este compromiso ha quedado gravemente afectado por la crisis económica que está creando muy serias dificultades, en especial en la lucha contra el paro y en el mantenimiento de un estatus económico mínimo para todas las familias.

Este es el gravísimo problema planteado para cuya solución hay que tener en cuenta, como punto de partida, que los valores que proclama la Constitución de libertad, justicia, igualdad, no sólo formal, los derechos y deberes que consagra, y las directrices de la política económica y social, marcan unos objetivos claros que vinculan a los poderes públicos, aun cuando la vinculación a los fines sea compatible con la elección de diversos medios para llevarlos a cabo de acuerdo con el valor del pluralismo político. En todo caso, hay que señalar la necesidad de que mantenga con claridad cuál es la última finalidad del Estado social de derecho, que no puede confundirse con un Estado asistencial, distinguiendo claramente los fines — que vinculan a todos—, y los medios — que pueden ser distintos de acuerdo con las diversas ideologías de conformidad con el pluralismo político ${ }^{3}$.

II. Las CUestiones QUe Planteaba la incorporación de EsPaña a la CoMUNIDAD ECONÓMICA EUROPEA. LA CONVERGENCIA COMO VÍA DE SOLUCióN

La incorporación de España a las Comunidades Europeas ha planteado desde la perspectiva constitucional, entre otras cuestiones, la

2 En este sentido I. Sotelo (2014), España a la salida de la crisis (la sociedad dual del capitalismo financiero), Barcelona: Icaria, págs. 31 y ss., considera las tensiones que históricamente se han producido entre el capitalismo y democracia, y la evolución que ha dado lugar a que el capitalismo haya pasado a ser consustancial con la democracia.

Asimismo, en las págs. 57 y ss., pone de manifiesto que pese a que Estado social y Estado de bienestar se utilizan como sinónimos importa tener clara la diferencia entre ambos. El Estado social se inventó en el último tercio del siglo xIX en la Alemania de Bismarck, y es una creación dirigida a amortiguar la lucha de clases, mediante el trípode del seguro de enfermedad, invalidez y vejez; el Estado de bienestar en cambio surge después de la Segunda Guerra Mundial en algunos pocos países del norte de Europa, al principio en el Reino Unido, con el ánimo de corregir las deficiencias más palpables del capitalismo. Solo con el pleno empleo puede hablarse del Estado de bienestar.

3 Sobre estas consideraciones véase R. Gómez Ferrer-Morant (1991), «La reserva al sector público de recursos o servicios esenciales», en S. M. Retortillo BAQuer (coord.), Estudios sobre la Constitución española (Homenaje al Prof. García de Enterría), t. V (págs. 3803-3837, esp. 3834-3837), Madrid: Civitas. 
compatibilidad de esta incorporación con el Estado social y democrático de derecho.

Esta cuestión se planteaba porque la finalidad inicial perseguida por el Tratado Constitutivo de la Comunidad Económica Europea era sustancialmente económica y no política, y consistía en el establecimiento de un mercado interior común caracterizado por la supresión entre los Estados miembros de los obstáculos a la libre circulación de mercancías, personas, servicios y capitales. En definitiva, desde la perspectiva de la libertad y de la igualdad, la Comunidad se circunscribía a un objetivo limitado de carácter económico como es la libertad de circulación - ya indicada - que se traducía en la igualdad de trato de los nacionales de los Estados miembros y en la libre competencia. A tal efecto los Estados miembros habían atribuido competencias en este ámbito a la Comunidad; pero resulta que las competencias se encuentran entrecruzadas de tal forma que en el ejercicio de una competencia atribuida la Comunidad podía incidir en el ejercicio de otras no atribuidas y este entrecruzamiento había de dar lugar, lógicamente, a problemas de relación entre el derecho de la Comunidad y el de los Estados miembros.

En concreto, la cuestión que se planteaba era la de determinar si el derecho comunitario, dictado en el ejercicio de las competencias atribuidas por los Estados, podía incidir en cualquier ámbito y gozaba también de superioridad en el mismo. Dicho en otras palabras ¿el derecho de la Comunidad es superior al derecho de los Estados sin limitación, de tal forma que éstos no puedan inaplicarlo, o dicha superioridad se encontraba limitada por el principio de atribución?

Si se admitía la superioridad del derecho dictado por la Comunidad, como un derecho autónomo, desconectado de su origen - y por tanto del principio de atribución de competencias-, la consecuencia era que la superioridad del derecho comunitario se traducía en la primacía de la libertad de circulación sobre todas las demás, de tal forma que se convertía en el valor superior que se imponía sin limitación alguna.

Y esta primacía podía plantearse incluso en términos extremos. ¿Qué sucedía cuando el derecho comunitario afectara a derechos fundamentales de los ciudadanos de alguno de los Estados? ¿Debía seguir manteniéndose la superioridad del derecho comunitario y afirmarse, en definitiva, que la incorporación había supuesto una mutación constitucional? ¿O debía entenderse que el ámbito del derecho comunitario estaba limitado por el principio de atribución y que, al menos sustancialmente, debía respetar unos límites implícitos basados en que la atribución de competencia se había efectuado en el ámbito de las Constituciones de cada uno de los Estados miembros? 
Como sabemos, el Tribunal de Justicia de Luxemburgo ha dado a esta cuestión una respuesta tajante en el sentido de mantener la superioridad del derecho comunitario - no sólo del primario sino también del derecho derivado- sobre el derecho de los Estados, entendiendo que el derecho dictado por la Comunidad en el ejercicio de sus competencias no se encuentra limitado por el derecho de los Estados miembros, ni tan siquiera por la Constitución de cada uno. De esta forma y a través de los principios de primacía del derecho comunitario y desplazamiento del derecho inter$\mathrm{no}^{4}$, y efecto directo de las Directivas, el Tribunal ha sentado una doctrina contundente acerca de la superioridad del derecho comunitario ${ }^{5}$.

Esta doctrina creaba un grave problema a los Estados, porque el derecho comunitario podía entrar en colisión con la Constitución y con los derechos fundamentales. En el terreno práctico, este problema se traducía en determinar si los jueces estatales podían acordar la inaplicación del derecho comunitario por entender que se excedía de los límites del principio de atribución de competencias al incidir sobre otras que no le habían sido atribuidas.

Esta cuestión ha dado lugar a diversos problemas en algunos de los Estados miembros, en los que, en términos generales y con diversas soluciones técnicas, se ha impuesto la tesis de la superioridad del derecho comunitario ${ }^{6}$.

\footnotetext{
${ }^{4}$ A partir de la Sentencia de 15 de julio de 1964, as. Costa c. ENEL. La primacía de las normas comunitarias ha sido afirmada por el TJCE en otras muchas sentencias, como, por citar algunas, la S. Politi, de 14 de diciembre de 1971; S. Marimex, de 7 de marzo de 1972; S. Bussone, de 30 de noviembre de 1978.

${ }^{5}$ En relación con el efecto directo de las Directivas, cuando desde el punto de vista de su contenido no estén sujetas a condición alguna y sean lo suficientemente precisas y el Estado no haya adaptado el derecho nacional a las Directivas en el plazo señalado o haya procedido a una adaptación incorrecta (SS del Tribunal de Justicia de 19 de enero de 1982 - as. Beckery de 26 de febrero de 1986 - as Marshall-) conviene recordar que los particulares no sólo pueden invocarlo ante los tribunales jurisdiccionales nacionales, sino que a la Administración Pública, incluida la Administración local, le incumbe la obligación de aplicar la Directiva y de no aplicar las disposiciones de carácter nacional que la incumplan (S. Fratelli Costanzo de 22 de junio de 1989).

${ }^{6}$ En este sentido, conviene recordar algunos casos relevantes: así, las sentencias del Tribunal Constitucional italiano de 27 de diciembre de 1973 - (as. Frontini) - y de 8 de junio de 1984 (as. Granitel), que admiten la superioridad del derecho comunitario partiendo de la transferencia de funciones efectuada conforme al artículo 11 de la Constitución; la Sentencia del Tribunal de Casación de 24 de mayo de 1975, as. Jacques Vabre, dictada con fundamento en el artículo 55 de la Constitución y en la naturaleza específica del derecho comunitario, así como también el Arrêt del Consejo de Estado recaído en el asunto Nicolo en 1990; o el principio de equivalencia en materia de derechos constitucionales, tomado en consideración por el Tribunal Constitucional en la Sentencia Solange II de 22 de octubre de 1986 y Soweit de 12 de mayo de 1989; por su parte, el Tribunal Constitucional español ha considerado detenidamente la relación entre el derecho de la Unión Europea y el derecho constitucional, con especial referencia a los derechos fundamentales y libertades públicas [ss. 215/2014, 232/2015]; mientras el Tribunal Supremo ha aplicado sin duda alguna la primacía del derecho comunitario desde la incorporación de España.
} 
La posición rotunda del Tribunal de Justicia de Luxemburgo era probablemente una solución radical, aconsejada por la necesidad de autoafirmar la Comunidad frente a los Estados y de conseguir los objetivos de la Comunidad que, de otra forma, se hubieran podido convertir en una meta inalcanzable.

Pero, sin perjuicio de ello, resulta patente que este planteamiento no se ajustaba a los valores de libertad, igualdad y justicia que se habían plasmado expresa e implícitamente en las Constituciones de los Estados miembros. Y por tanto era lógico que las fricciones existentes se superaran buscando una solución que permitiera mantener la superioridad del derecho comunitario y el respeto al menos, si no la incorporación, de los valores y los principios inspiradores de los Estados miembros.

De esta forma se va a producir la convergencia del derecho comunitario con el derecho de los Estados miembros.

La incorporación de los valores y principios caracterizadores de la Constitución de los Estados miembros no presentaba una dificultad jurídica relevante; pues, en efecto, dado que la Comunidad tenía las competencias en virtud de la atribución efectuada por los Estados en el Tratado de Roma, resultaba posible modificar el Tratado en el sentido que decidieran los Estados para que tal asunción se llevara a cabo.

Ahora bien, como fácilmente se comprende, el problema no era sólo de carácter formal o procedimental. La modificación del Tratado y la asunción de determinados valores y principios suponía un reto político de gran trascendencia, en cuanto implicaba la decisión de avanzar en el camino de la unidad política superando los objetivos iniciales de carácter únicamente económico. En todo caso, debe hacerse constar que esta idea existía ya desde el momento inicial, en el que, no obstante, se entendió que el objetivo de carácter económico era el que más se ajustaba a las posibilidades reales inmediatas.

Ello explica que el camino para pasar de la Comunidad Económica Europea a la Comunidad Europea ${ }^{7}$ y luego a la Unión Europea, haya sido recorrido en varias etapas que van a culminar con el Tratado de la Unión Europea celebrado en Lisboa el 13 de diciembre de 2007 y el de Funcionamiento de la misma fecha.

La incorporación al ordenamiento de la Comunidad de los principios y valores indicados se efectúa a lo largo de un proceso de evolución, que se refleja en diversos hitos, como son el Acta Única Europea y los

7 El artículo G) del Tratado de Maastricht establece que: «El Tratado de la Comunidad Económica Europea se modificará de conformidad con las disposiciones del presente artículo, a fin de constituir una Comunidad Europea». Los términos «Comunidad Económica Europea» se sustituirán por los términos «Comunidad Europea». 
Tratados de Maastricht, Amsterdam y Niza. A lo largo de estas etapas se producirá tal incorporación en una primera etapa como límite del principio de atribución y, más adelante, también en sentido positivo, es decir, como objetivos cuya consecución persigue la Comunidad, a través de políticas concretas.

En esta línea de avance es necesario mencionar, como antecedente, el Acta Única Europea, de 17 y 28 de febrero de 1986, cuyo objetivo esencial era conseguir para el 31 de diciembre de 1992 la realización de un verdadero mercado interior, y en cuyo preámbulo se expresa la voluntad de los firmantes de promover conjuntamente la democracia basándose en los derechos fundamentales reconocidos en las Constituciones y leyes de los países miembros, en el Convenio Europeo para la Protección de los Derechos Humanos y de las Libertades Fundamentales y en la Carta Social Europea, en particular la libertad, la igualdad y la justicia social ${ }^{8}$.

Pero es en el Tratado de Maastricht de 7 de febrero de 1992 donde se va a producir ya un avance político sustancial. En efecto, en este Tratado se constituye la Unión Europea (Artículo A), cuyos objetivos trascienden ya del planteamiento meramente económico para extenderse a objetivos de política exterior, seguridad común, justicia e interior y a la creación de la ciudadanía de la Unión (que incluye, entre otros derechos, el de votar y ser elegido en las elecciones municipales, lo que ha dado lugar a la modificación de constituciones de los Estados miembros y, entre ellas, de la española ${ }^{9}$ ), a la vez que establece nuevas políticas comunitarias, y una regulación de la cohesión económica y social ${ }^{10}$. Además, es necesario

\footnotetext{
${ }^{8}$ En concordancia con lo anterior en el Acta se regula la Cohesión Económica y Social (añadiendo un Título $\mathrm{V}$ en la Tercera Parte del Tratado), a cuyo efecto se prevé la utilización adecuada de los Fondos con finalidad estructural (Feder, Fondo Social Europeo, FEOGA) introduciendo las modificaciones necesarias para precisar y racionalizar sus funciones.

9 Modificación del artículo 13 de la Constitución española, de 27 de agosto de 1992.

10 Esta regulación se establece a fin de promover un desarrollo armonioso del conjunto de la Comunidad, y en particular, de reducir las diferencias entre los niveles de desarrollo de la diversas regiones y el retraso de regiones menos favorecidas, incluidas las zonas rurales; a cuyo efecto, la Comunidad apoyará la consecución de estos objetivos en la actuación que realiza mediante los Fondos con finalidad estructural (FEOGA, FEDER, Fondo Social Europeo), del Banco Europeo de Inversiones y de los otros instrumentos existentes, a la vez que se acuerda crear un Fondo de Cohesión antes del 31 de diciembre de 1993 que proporcione una contribución financiera a proyectos en sectores de medio ambiente y de las redes transeuropeas en materia de infraestructuras del transporte.

Asimismo, es importante recordar que el Tratado de Maastricht modifica el artículo 123 del Tratado Constitutivo de la Comunidad, relativo al Fondo Social Europeo, en el sentido de atribuirle también la finalidad de facilitar la adaptación de los trabajadores a las transformaciones industriales y a los cambios de los sistemas de producción, especialmente la formación y la reconversión profesionales, lo que se ha traducido en importantes programas de formación que han facilitado la reinserción de los trabajadores en paro y la actualización de los conocimientos de los trabajadores.
} 
resaltar que el Tratado de Maastricht incorpora una delimitación de las competencias de la Comunidad, al establecer en el artículo F, núms. 1 y 2) que ha de respetar los derechos fundamentales en los siguientes términos:

La Unión respetará los derechos fundamentales tal y como se garantizan en el Convenio Europeo para la Protección de los Derechos Fundamentales y de las libertades Públicas firmado en Roma en 4 de noviembre de 1950, tal y como resultan de las tradiciones constitucionales comunes a los Estados miembros como principios generales de Derecho Comunitario.

La efectividad de estos derechos no son un objetivo propio de la Comunidad sino un límite - respeto- para su actuación. De esta forma, y en el camino de la convergencia, se soluciona una de las fricciones más importantes que se planteaban entre el derecho de la Comunidad y el de los Estados miembros. Debe hacerse notar, sin embargo, que el Tratado de Maastricht era plenamente consciente de su significado limitado en el camino de la integración, como confiesa expresamente su artículo F («El presente tratado constituye una nueva etapa en el proceso creador de una Unión cada vez más estrecha entre los pueblos de Europa»).

En este camino de incorporación de valores y principios, el Tratado de Amsterdam de 2 de octubre de 1997 va a dar nueva redacción al punto 1 del artículo F del Tratado de Maastricht («la Unión respetará la identidad nacional de los Estados miembros, cuyos sistemas de gobierno se basarán en los principios democráticos») en un sentido positivo, al decir que,

1.- La Unión se basa en los principios de libertad, democracia respecto de los derechos humanos y de las libertades fundamentales y el Estado de derecho, principios que son comunes a todos los Estados miembros.

El Tratado de Amsterdam implica un cambio de perspectiva, porque incorpora en sentido positivo los principios de libertad democracia, respecto de los derechos humanos y de las libertades fundamentales y el Estado de derecho "principios que son comunes a todos los Estados miembros», al afirmar que constituyen la base de la Unión Europea.

El Tratado de Niza de 26 de enero de 2001 ha tenido el claro objetivo de preparar la Unión Europea para las futuras ampliaciones, por lo que el debate de fondo sobre la posible evolución política de la Unión se pospone a la Conferencia Intergubernamental prevista para el año 
2004 en la «Declaración sobre el futuro de la Unión». En esta declaración se adelantan las cuestiones a tratar y entre ellas el estatuto de la Carta de los Derechos Fundamentales de la Unión Europea, proclamada en Niza el 7 de diciembre de 2000, Carta que no se ha incorporado al propio Tratado.

Finalmente el Tratado por el que se instituye una Constitución para Europa, firmado en Roma el 29 de octubre de 2004, abre una nueva etapa que ha culminado con el Tratado de la Unión Europea celebrado en Lisboa el 13 de diciembre de 2007, y el de Funcionamiento de la Unión de la misma fecha, que culminan esta evolución; así lo acredita su contenido, para cuya valoración es necesario partir de su artículo 6, que «reconoce los derechos, libertades y principios enunciados en la Carta de los Derechos Fundamentales de la Unión Europea de 7 de diciembre de 2000, tal como fue adoptada en 12 de diciembre de 2007, la cual tendrá el mismo valor jurídico de los Tratados».

La consideración del Tratado de la Unión desde la perspectiva del Estado social y democrático de derecho confirma la plena convergencia del derecho de la Unión. Así, en el Preámbulo del Tratado se afirma que se inspira en la herencia cultural, religiosa y humanista de Europa a partir de la cual se han desarrollado los valores universales de los derechos inviolables e inalienables de la persona, así como la libertad, la democracia, la igualdad y el Estado de derecho; en el propio Preámbulo se confirma la adhesión a los principios de libertad, democracia y respeto de los derechos humanos y de las libertades fundamentales ${ }^{11}$; y expone también la decisión de promover el progreso social y económico de los pueblos, teniendo en cuenta el principio del desarrollo sostenible, dentro de la realización del mercado interior y del fortalecimiento de la cohesión y de la protección del cambio climático.

El Tratado de la Unión refleja ya de forma expresa la distinción entre los valores en que se basa la Constitución y que son su fundamento último, y los principios generales de carácter jurídico-político que forman la estructura del conjunto, aun cuando la distinción entre una y otra categoría aparezca desdibujada en algún caso; en efecto, su artículo 2 enumera los valores que constituyen el Fundamento de la Unión en los siguientes términos:

La Unión se fundamenta en los valores de respeto a la dignidad humana, libertad, democracia, igualdad, Estado de derecho y respeto a los derechos

11 Tal y como aparecen definidas en la Carta Social Europea firmada en Turín en 18 de octubre de 1961 y en la Carta Europea de los Derechos Sociales fundamentales de los trabajadores de 1989. 
humanos, incluidos los derechos de personas pertenecientes a minorías. Estos valores son comunes a los Estados miembros en una sociedad caracterizada por el pluralismo, la tolerancia, la justicia, la solidaridad y la no discriminación ${ }^{12}$.

En fin, de todo lo expuesto resulta con claridad que la incorporación de España a las Comunidades Europeas (Unión Europea) no afecta negativamente al Estado social y democrático establecido por el artículo 1 de la Constitución, sino que contribuye a su plena efectividad.

Por otra parte, y en relación a las competencias de la Unión, sigue siendo de aplicación el principio de atribución, tal y como expresa el artículo 5 [antiguo 5 (E)]: «La delimitación de las competencias de la Unión se rige por el principio de atribución» $\mathrm{y}$ «En virtud del principio de atribución, la Unión actúa dentro de las competencias que las atribuyen los Estados miembros en los Tratados para lograr los objetivos que éstos determinan».

III. LA APORTACión DE LA UNiÓN EuROPEA A LA EFECTIVIDAD DEL Estado SOCIAL Y DEMOCRÁTICO DE DERECHO

\section{Introducción}

La aportación de la Unión Europea en el ámbito social resulta ya de todo lo expuesto, y es también muy clara en materia de medio ambiente, dada además la existencia de buen número de directivas traspuestas en la legislación española.

Por ello, voy centrar la atención en dos aspectos que me parecen de especial importancia para la efectividad del Estado social, como son la lucha contra la corrupción y la efectividad de los principios rectores de la política económica y social.

\section{La lucha contra la corrupción}

El funcionamiento del Estado social y democrático de derecho requiere la inexistencia de corrupción, más allá de supuestos aislados y excepcionales que siempre pueden existir.

12 El tratado, como se observa, efectúa una amplia enumeración de valores en su artículo 2, aun cuando puede distinguirse en el propio texto entre los valores y las construcciones técnico-jurídicas que se incorporan como principios estructurales de la Constitución con la finalidad de que puedan hacerse efectivos todos los valores. 
La corrupción se define en sentido amplio por el Informe de la Comisión al Consejo y al Parlamento Europeo sobre la lucha contra la corrupción en la UE [COM(2014)38 final] de 3 de febrero de 2014, como cualquier «abuso de poder para obtener réditos privados». El Informe abarca los actos específicos de corrupción y las medidas que los Estados miembros adoptan para prevenir o sancionar específicamente los actos de corrupción definidos en la legislación, y también menciona una serie de ámbitos y medidas que influyen en el riesgo de corrupción y la capacidad para luchar contra ella.

El Informe expone en su Introducción la grave incidencia de la corrupción para la justicia social, el Estado de derecho y la democracia, en los siguientes términos:

La corrupción supone un perjuicio grave para la economía y la sociedad en su conjunto. Muchos países del mundo padecen una arraigada corrupción que frena el desarrollo económico, socava la democracia y daña la justicia social y el Estado de derecho. Los Estados miembros de la UE no son inmunes a esta realidad. La corrupción varía en su naturaleza y alcance de un país a otro, pero afecta a todos los Estados miembros. Compromete la buena gobernanza, la correcta gestión de los fondos públicos y la competitividad de los mercados. En casos extremos, mina la confianza de los ciudadanos en las instituciones y los procesos democráticos.

La actuación decidida contra la corrupción en todos los ámbitos es por tanto absolutamente imprescindible. Ello requiere no solo la existencia de esta convicción - que sin duda existe- sino la fortaleza necesaria para observar un comportamiento coherente.

Cuando este comportamiento coherente no se produce, y se fractura la relación de confianza entre electores y elegidos que es esencial para el funcionamiento del Estado social y democrático de derecho, la reacción social y la sensibilidad política dan lugar a una toma en consideración por el sistema jurídico.

Esta reacción se ha producido tanto en el ámbito de la Unión Europea como en el ámbito estrictamente interno.

Así, en cuanto a la Unión Europea, es importante poner de relieve que el Informe de la Comisión al Consejo y al Parlamento Europeo sobre la lucha contra la corrupción en la UE [COM(2014)38 final], al que ya nos hemos referido, dedica su Anexo noveno a España, y expone de forma detallada las principales características y contexto (con referencia entre otros extremos a las modificaciones legales que se están produciendo) y las cuestiones que se encuentran en el punto de mira, 
que son la financiación de los partidos políticos, la corrupción a nivel regional y local, la contratación pública, la transparencia y el acceso a la información ${ }^{13}$.

Con posterioridad a este Informe, y en línea con las futuras modificaciones legislativas a que hace referencia ${ }^{14}$, se han dictado la Ley $3 / 2015$, de 30 de marzo, de control de la actividad económico-financiera de los partidos políticos, y la Ley Orgánica 1/2015, de 30 de marzo, por la que se modifica el Código Penal.

Esta Ley Orgánica 1/2015, además de introducir determinadas modificaciones para reforzar la punición de los delitos contra la corrupción en el ámbito de la Administración pública, introduce un nuevo Título XIII bis en el Código Penal con la rúbrica de «De los delitos de financiación ilegal de los partidos políticos» (arts. 304 bis y 304 ter). Como indica la Exposición de Motivos, la reforma da respuesta penal a la necesidad de definir un tipo penal específico para estos actos delictivos, ya que en la vigente legislación española no existe un delito concreto que esté tipificado como delito de financiación ilegal de partidos políticos. Con esta modificación se castigará a aquellas personas que acepten y reciban donaciones ilegales o que participen en estructuras u organizaciones cuyo principal objeto sea el de financiar ilegalmente a un partido político.

Ello no significa obviamente que con anterioridad la corrupción estuviera admitida por el sistema jurídico, como resulta con toda evidencia de la intensa actuación de los jueces y tribunales, pero sí responde a la necesidad de definir y precisar de forma acabada las conductas incompatibles con la necesidad de observar un comportamiento ético — que se positiviza- que es el soporte del Estado social.

13 Sobre la lucha contra la corrupción en la Unión Europea y el primer Informe de la Comisión [COM (2014)38 final], al que seguirán otros cada dos años, véase A. LlORENTE PÉREz (2014), «El reto de la lucha contra la corrupción en la Unión Europea», Aranzadi Unión Europea, 10, págs. 41-57.

14 Al exponer el marco jurídico, el Anexo sobre España se refiere a la situación existente en los siguientes términos: "La evolución llevada a cabo en 2011 en el marco de la Convención de las Naciones Unidas contra la Corrupción determinó que España implantara en gran parte el marco jurídico penal de lucha contra la corrupción. El Grupo de Estados contra la Corrupción (GRECO) del Consejo de Europa también observó en su segundo informe relativo a la tercera ronda de evaluación, publicado en julio de 2013, que la tipificación como delito de cohecho y el tráfico de influencias en el Código Penal español se ajusta en gran medida a las normas del Consejo de Europa». El propio Informe se refiere a diversas leyes dictadas y a una serie de modificaciones legislativas que se están estudiando en el momento del Informe. 
3. La efectividad de los principios rectores de la politica económica y social

Una de las consecuencias que ha producido la crisis económica ha sido, como ya se ha indicado, la ruptura del compromiso propio del Estado social y democrático de derecho entre la libertad y la igualdad.

Esta quiebra ha sido especialmente sensible en España en relación con el principio rector contenido en el art. 47 de la Constitución, que afirma que todos los españoles tienen derecho a una vivienda digna y adecuada; principio rector que tiene el alcance que establece el artículo 53.3 de la Constitución al decir que:
Artículo 53.
[...]
3. El reconocimiento, el respeto y la protección de los principios reconoci- dos en el Capítulo $3^{\circ}$ ( De los principios rectores de la política social y econó- mica») informarán la legislación positiva, la práctica judicial y la actuación de los poderes públicos. Sólo podrán ser alegados ante la Jurisdicción ordi- naria de acuerdo con lo que dispongan las leyes que los desarrollen.

La crisis económica ha dado lugar a miles y miles de desahucios producidos por impago de créditos hipotecarios, lo que ha planteado la necesidad de determinar cómo el sistema jurídico podía hacer frente a esta situación. Se trata de una cuestión absolutamente relevante, como fácilmente se comprende.

Esta cuestión ha sido considerada por el derecho de la Unión Europea y por el derecho del Estado.

La vía jurídica aplicada en relación con este problema ha consistido en una combinación del principio rector contenido en el artículo 47 - derecho a una vivienda digna y adecuada - con el de protección de los usuarios y consumidores, que establece el artículo 51 de la Constitución, al decir que los poderes públicos garantizarán la defensa de los consumidores y usuarios, protegiendo mediante procesos eficaces la seguridad, la salud y los legítimos intereses económicos de los mismos; principio rector con el que conecta el relativo al derecho a la vivienda, dado que los compradores de vivienda tienen la condición de consumidores, como veremos.

Esta actuación conjunta de los dos principios rectores se ha llevado a cabo, además, en conexión con el derecho a la tutela judicial efectiva que establece el artículo 24 de la Constitución, y el artículo 47, «Derecho a la tutela judicial efectiva y a un juez imparcial» del Acuerdo de 
7 de diciembre de 2000, «Carta de los Derechos Fundamentales de la Unión Europea», que ha adquirido valor jurídico en virtud del artículo 6.1 del Tratado de la Unión Europea; pues, en efecto, este precepto establece que la Unión reconoce los derechos, libertades y principios enunciados en la Carta de los Derechos Fundamentales de la Unión Europea de 7 de diciembre de 2000, tal como fue adoptada el 12 de diciembre de 2007 en Estrasburgo, la cual tendrá el mismo valor jurídico que los Tratados.

La actuación se ha realizado a partir del derecho de la Unión Europea, y en concreto de la Directiva 93/13 CEE del Consejo, de 15 de abril de 1993, sobre cláusulas abusivas en los contratos celebrados con consumidores cuya transposición se efectuó por la Ley 7/1998, de 14 de abril, de Condiciones Generales de Contratación.

Esta Ley introdujo determinadas modificaciones en la Ley 26/1984, de 19 de julio, General para la Defensa de los Consumidores y Usuarios, y entre ellas la modificación de su artículo 10 relativo a los requisitos que debían cumplir las cláusulas, condiciones o estipulaciones que se apliquen a la oferta o promoción de productos o servicios y cláusulas no negociadas individualmente relativas a tales productos o servicios. Y además añadía una «Disposición Adicional Primera. Cláusulas abusivas», que establecía una enumeración abierta de las cláusulas que tendrían el carácter de abusivas. Y finalmente el Real Decreto Legislativo 1/2007, de 16 de noviembre, aprueba el T. R. de la Ley General de la Defensa de los Consumidores y Usuarios cuyo artículo 82 se refiere al concepto de cláusulas abusivas y efectúa una enumeración abierta.

Esta enumeración abierta iba a plantear la cuestión de si determinadas claúsulas de contratos de préstamo hipotecario celebrados con los consumidores eran o no abusivas. Cuestión que cobró especial importancia a partir del planteamiento de una cuestión prejudicial por el Juzgado mercantil núm. 3 de Barcelona resuelta por la STJUE de 14 de marzo de 2013, Asunto 415/11, y de otra planteada por la Audiencia Provincial de Castellón resuelta por la STJUE de 17 de julio de 2014, asunto C-169/14.

La Sentencia de 14 de marzo de 2013 resuelve dos cuestiones prejudiciales: en cuanto a la primera ${ }^{15}$, pone de manifiesto la inadecuación

15 Mediante su primera cuestión, el órgano jurisdiccional remitente pide sustancialmente que se dilucide si la Directiva debe interpretarse en el sentido de que se opone a una normativa de un Estado miembro, como la controvertida en el litigio principal, que, al mismo tiempo que no prevé, en el marco del procedimiento de ejecución hipotecaria, la posibilidad de formular motivos de oposición basados en el carácter abusivo de una cláusula contenida en un contrato celebrado entre un consumidor y un profesional, no permite que el juez que conozca del proceso declarativo, competente para apreciar el carácter abusivo de dicha cláusula, adopte medidas 
al derecho de la Unión de la regulación del proceso de ejecución de los bienes hipotecados en la Ley de Enjuiciamiento Civil (arts. 695 y 698) y complementariamente los artículos 131 y 133 de la Ley Hipotecaria, para concluir en el fallo que: «La Directiva 93/13/CEE del Consejo, de 5 de abril de 1993, sobre las cláusulas abusivas en los contratos celebrados con consumidores, debe interpretarse en el sentido de que se opone a una normativa de un Estado miembro, como la controvertida en el litigio principal, que, al mismo tiempo que no prevé, en el marco del procedimiento de ejecución hipotecaria, la posibilidad de formular motivos de oposición basados en el carácter abusivo de una cláusula contractual que constituye el fundamento del título ejecutivo, no permite que el juez que conozca del proceso declarativo, competente para apreciar el carácter abusivo de esa cláusula, adopte medidas cautelares, entre ellas, en particular, la suspensión del procedimiento de ejecución hipotecaria, cuando acordar tales medidas sea necesario para garantizar la plena eficacia de su decisión final»; y, en cuanto a la segunda cuestión prejudicial, efectuaba importantes consideraciones sobre los criterios que debería utilizar el juez para apreciar si tienen carácter abusivo las cláusulas referentes al vencimiento anticipado en los contratos de larga duración, a la fijación de intereses de demora y al pacto de liquidez.

En relación con esta sentencia, debe señalarse que su contenido se reflejó en la Ley 1/2013, de 14 de mayo, de medidas para reforzar la protección a los deudores hipotecarios, reestructuración de la deuda y alquiler social, que regula la suspensión de los lanzamientos sobre viviendas habituales de colectivos especialmente vulnerables; introduce medidas de mejora de mercado hipotecario con modificación de la Ley Hipotecaria y limitación del tipo de intereses de demora, regulación de sociedades de tasación, información de riesgo, hipoteca inversa; modificación de la Ley de Enjuiciamiento Civil (LEC) en cuanto a la regulación del procedimiento de ejecución hipotecaria; protección de deudores hipotecarios sin recursos; código de buenas prácticas; y promoción por el Gobierno de un Fondo Social de Viviendas; a lo que debe añadirse la modificación del ap. 4 del artículo 695 de la LEC por la D.F. $3^{\text {a }}$ del Real Decreto Ley 11/2014, de 5 de septiembre.

La segunda Sentencia del TJUE, de 17 de julio de 2014, dictada en el asunto C-169/14 se dicta en relación con dos cuestiones prejudiciales suscitadas por el procedimiento de ejecución hipotecaria y planteadas con posterioridad a la modificación de la LEC por la citada Ley de 2013.

cautelares que garanticen la plena eficacia de su decisión final. 
Hacemos notar que el planteamiento de la cuestión prejudicial se basa también en el artículo 47 de la Carta de Derechos Fundamentales que consagra el derecho a la tutela judicial efectiva, y que la Sentencia expone la trascendencia de este derecho en relación con la observancia por los Estados de su obligación de garantizar la efectividad de los derechos que la Directiva 93/13 confiere a los justiciables frente a la aplicación de cláusulas abusivas, efectividad que implica una exigencia de tutela judicial, consagrada asimismo en el artículo 47 de la Carta, que el juez nacional debe observar; precepto que además consta en el fallo, dado que la cuestión planteada se refería en definitiva a la vulneración o no de la igualdad de partes en un proceso ${ }^{16}$.

Con posterioridad a esta segunda Sentencia, y como consecuencia de la misma, la Ley 9/2015, de 25 de mayo (D. F. $3^{\text {a }}$ ), modificó el apartado cuarto del artículo 695 de la Ley de Enjuiciamiento Civil, en el sentido de admitir el recurso de apelación contra el auto que desestime la oposición a la ejecución por la causa fundada en el carácter abusivo de una cláusula contractual que constituya el fundamento de la ejecución o que hubiese determinado la cantidad exigible.

En conexión con el derecho de la Unión Europea se ha producido una importante jurisprudencia del Tribunal Supremo; por razones obvias de espacio, me limito a referirme a la trascendental Sentencia de 9 de mayo de 2013 dictada en el recurso de casación $n^{\circ}$ 485/2012, que efectúa un examen completo del control de las cláusulas abusivas a partir del derecho de la Unión (F. D. Sexto), las condiciones generales sobre el objeto del contrato y su imposición (FF. D. séptimo y octavo), las condiciones generales en sectores regulados, con referencia a los préstamos hipotecarios (F. D. noveno), y su aplicación al recurso planteado (FF. DD.: décimo y siguientes), lo que en definitiva lleva a una Sentencia que declara la nulidad de las cláusulas suelo contenidas en las condiciones generales de los contratos suscritos con consumidores (que especifica en los apartados 2, 3 y 4 del Antecedente de hecho

16 El fallo de la Sentencia dice así: «El artículo 7, apartado 1, de la Directiva 93/13/CEE del Consejo, de 5 de abril de 1993, sobre las cláusulas abusivas en los contratos celebrados con consumidores, en relación con el artículo 47 de la Carta de los Derechos Fundamentales de la Unión Europea, debe interpretarse en el sentido de que se opone a un sistema de procedimientos de ejecución, como el controvertido en el litigio principal, que establece que el procedimiento de ejecución hipotecaria no podrá ser suspendido por el juez que conozca del proceso declarativo, juez que, en su resolución final, podrá acordar a lo sumo una indemnización que compense el perjuicio sufrido por el consumidor, en la medida en que éste, en su condición de deudor ejecutado, no puede recurrir en apelación contra la resolución mediante la que se desestime su oposición a la ejecución, mientras que el profesional, acreedor ejecutante, sí puede interponer recurso de apelación contra la resolución que acuerde el sobreseimiento de la ejecución o declare la inaplicación de una cláusula abusiva». 
primero) por las razones que indica en el fallo ${ }^{17}$, condena a eliminar dichas cláusulas en los contratos en que se insertan y a cesar en su utilización, y declara que no ha lugar a la retroactividad de esta Sentencia que no afectará a las situaciones definitivamente decididas por resoluciones con fuerza de cosa juzgada ni a los pagos ya efectuados en la fecha de publicación de la Sentencia; pronunciamiento este último que está pendiente de confirmación o anulación por el Tribunal de Justicia de la Unión Europea ${ }^{18}$.

Además de lo expuesto, debe hacerse notar que también se ha utilizado la vía normativa, tanto en el orden interno como en el derecho de la Unión.

Así en el orden interno, y en conexión con la Ley de Economía Sostenible 2/2011, de 4 de marzo, es importante la Orden EHA/2899/2011, de 28 de octubre, de transparencia y protección de los clientes de servicios bancarios (implantación de medidas de transparencia, préstamo responsable).

Y, asimismo, la Ley 25/2015, de 28 de julio, de mecanismo de segunda oportunidad, reducción de la carga financiera y otras medidas de orden social.

Y en relación con el derecho de la Unión Europea, es muy importante la Directiva 2014/17/UE sobre contratos de crédito celebrados con los consumidores para la adquisición de bienes inmuebles de uso residencial, porque parte de la crisis financiera y de la situación que se ha producido, que pone de manifiesto la necesidad de establecer un marco jurídico adecuado teniendo en cuenta que los consumidores y las empresas no se encuentran en la misma posición.

17 En efecto, el punto séptimo del fallo declara «la nulidad de las cláusulas suelo contenidas en las condiciones generales de los contratos suscritos con consumidores descritas en los apartados 2, 3 y 4 del antecedente de hecho primero de esta Sentencia por: a) La creación de la apariencia de un contrato de préstamo a interés variable en el que las oscilaciones a la baja del índice de referencia, repercutirán en una disminución del precio del dinero; b) La falta de información suficiente de que se trata de un elemento definitorio del objeto principal del contrato; c) La creación de la apariencia de que el suelo tiene como contraprestación inescindible la fijación de un techo; d) Su ubicación entre una abrumadora cantidad de datos entre los que quedan enmascarados y que diluyen la atención del consumidor en el caso de las utilizadas por [...]; e) La ausencia de simulaciones de escenarios diversos, relacionados con el comportamiento razonablemente previsible del tipo de interés en el momento de contratar, en fase precontractual; f) Inexistencia de advertencia previa clara y comprensible sobre el coste comparativo con otros productos de la propia entidad».

18 En relación con estas cuestiones, el Tribunal Supremo ha contemplado diversas situaciones; así, se ha referido al enriquecimiento injusto (así STS de 13 de enero de 2015, recurso núm. 1147/2013); ha puesto de relieve que la aplicación de la cláusula rebus sic stantibus ha de producirse con normalidad - y no con carácter excepcional- en las circunstancias actuales (SSTS de 30 de junio de 2014, recurso núm. 2250/2012, y de 15 de octubre de 2014, recurso núm. 2992/2012); y ha aplicado el error de consentimiento en las Sentencias 23 y 24/2016 de 3 de febrero, aplicable a los pequeños inversores, en la adquisición de acciones de Bankia. 
Dado que no es posible exponer todo el contenido de esta Directiva nos limitamos a señalar:

- que el Considerando tercero (3) expone (aunque algunos de los mayores problemas se produjeran fuera de la Unión), que «la crisis financiera ha demostrado que el comportamiento irresponsable de los participantes en el mercado puede socavar los cimientos del sistema financiero, lo que debilita la confianza de todos los interesados, en particular los consumidores, y puede tener graves consecuencias sociales y económicas. Numerosos consumidores han perdido la confianza en el sector financiero y los prestatarios han experimentado cada vez más dificultades para hacer frente a sus préstamos, provocando un aumento de los impagos y las ventas forzosas $[\ldots] »$.

- que el Considerando quinto (5), como consecuencia de lo anterior, indica que "para facilitar la emergencia de un mercado interior con un funcionamiento satisfactorio y un elevado grado de protección de los consumidores en lo que respecta a los contratos de crédito para bienes inmuebles, y para garantizar que los consumidores que busquen celebrar tales contratos puedan hacerlo con la confianza de que las entidades con las que entablen relación se comportan de manera profesional y responsable, es necesario establecer un marco jurídico adecuadamente armonizado a escala de la Unión en una serie de ámbitos [...]».

- que el Considerando núm. once (11) afirma que «dado que los consumidores y las empresas no están en la misma posición, no necesitan disponer del mismo grado de protección. Por lo que (Considerando 15) precisa que el objetivo de la Directiva consiste en garantizar que todos los consumidores que concluyan los contratos de crédito para bienes inmuebles disfruten de un elevado grado de protección que se refleja de forma clara en el articulado de la Directiva.

\section{Conclusión}

¿Qué nos pone de manifiesto todo lo expuesto?

En primer lugar, que en la consecución de la efectividad del Estado social y democrático se encuentran comprometidos todos los poderes 
del Estado; pero no sólo eso sino que, por medio de las normas que se dictan de obligatoria observancia, se encuentra comprometida toda la sociedad.

En segundo término, que el sistema jurídico no funciona como una máquina o, si se quiere, como una ciencia que pueda resolver los casos con una aplicación de normas jerarquizadas, sin más. Porque existen exigencias de los valores y principios que integran el sistema, con valor superior a la ley.

Y también, lo que es muy relevante, que los derechos constitucionales y los principios rectores se encuentran interconectados entre sí y con el derecho de la Unión Europea.

Además, también justifica que los tribunales disponen de grandes posibilidades en la interpretación y aplicación del sistema jurídico, partiendo de la Constitución y normas internas, y del derecho de la Unión Europea, que tienen un carácter convergente y acumulativo. 
